\title{
DETERMINATION OF THERMAL PERFORMANCE OF ROOF
}

\author{
K.Thirumaran', Jesna Mathew ${ }^{2}$ \\ ${ }^{1}$ Associate Professor, Department of Architecture, National Institute of Technology, Trichy, Tamilnadu, India \\ ${ }^{2}$ PG Student, Department of Architecture, National Institute of Technology, Trichy, Tamilnadu, India
}

\begin{abstract}
The thermal performance of roof is one of the most important aspects to achieve indoor thermal comfort in tropical buildings. The key element to determine the thermal performance is the heat transfer across the roof and its measurement. Heat transfer across the building roof system is now a crucial research topic that bears large consequences on energy consumption and conservation in buildings. Studies in this area require numerous analytical and numerical data validated by experimental results. This paper describes factors and a measuring technique of measurement that determine the thermal performance of roof. This measuring technique utilizes the capacity of thermocouple to measure the temperature difference between two places which are in contact with two different junctions of thermocouple. The main objective of this research is to experimentally validate the thermal performance of roof and also measuring technique using thermocouple. The material of roofing is an important parameter to determine the thermal performance. This research mainly focused on the thermal performance of reinforced cement concrete $(R C C)$ roof which is used as roofing material in tropical houses and blamed for indoor thermal discomfort. This study uses an experimental approach in which three RCC slabs of varying thickness is heated and measured the heat transfer across them. This work presents an experimental set up to demonstrate the measuring technique by constructing three models of RCC slab of varying thickness and instrumented with thermocouple. Inner and outer surface temperature data is collected for each model by heating them for a day. The measurement procedure is detailed with an examination of the time lag for heat flow through the three models due to the effect of thermal mass.
\end{abstract}

Keywords: Roof thermal performance, Measuring technology, Thermo couple, Experimental set up, Time lag

\section{INTRODUCTION}

The man has always striven to create a thermally comfortable environment. From ancient to present day the building traditions shows the different methods or designs to achieve thermal comfort. Today, creating the best possible thermally comfortable indoor climate is still one of the most important tasks while designing buildings. Thermal comfort refers to a state or condition of mind which express satisfaction with the thermal environment (ISO 7730)(Thermal comfort 2002).

'The worldwide economic and technological development requires higher energy demands and higher comfort expectations (heating and cooling systems)' (Madhumathi 2012). 'Buildings across the globe consume $60-70 \%$ of the total energy generated and are a major contributor to the greenhouse gases. The maximum share of this energy usage is in conditioning (heating or cooling) the building interiors' (Agrawal, 2012). This in turn provokes the consumption of large quantities of energy sources like fossil fuels which causes a severe impact on the environment (Madhumathi, 2012). In India, which has a tropical climate, passive thermal control of building envelope would result in major energy saving and minimizing the greenhouse gas emissions which would contribute to a green and sustainable development. 'The thermal performance of building envelope can make a significant contribution in reducing the overall building energy usage' (Matrosov 2007). The roof becomes the most exposed part of the building to the solar radiation during daylight hours and in tropics the angle of incidence is high in the hotter parts of the day. In India, specifically urban regions, our construction practices mainly involve reinforced cement concrete (RCC) as the roofing element, which is noted for its high thermal conductivity. Further to superior structural engineering technologies have given rise to deployment of thinner and thinner concrete thickness, ranging from under 90 to $150 \mathrm{~mm}$ (Energy, 2010). RCC slab retain the heat gained during the daytime and continue to emit heat for several hours and affecting the users comfort. If the roof system designed with respect to thermal comfort factors the atmosphere inside the building can be controlled to a great extent. And it can provide significant energy savings in cooled building.

Therefore a study on thermal performance of roofing system has a significant role in providing thermal comfort level and reducing cooling loads. It requires the determination of thermal performance of roof. This research is designed to study the determination of thermal performance of roof through experimental demonstration.

The primary aim is 1 . To Study the parameters that determine the roof thermal performance. 2. Experimentally demonstrate and analyses the effect of varying thickness of RCC slab on its thermal performances. That is changing the parameters of thermal resistance. 3. Developing a measuring technique for thermal performance by an experimental approach. 
The secondary objectives are 1.To study the thermal behavior of RCC slabs. 2. To study about the heat transfer through the material. 3. To study about the measurement of surface temperature using thermocouple.

The thermal performance can be determine in terms of time lag of heat flow and decrement factor for the three models of RCC slabs of varying thickness. The measurement technique utilizes thermocouple to collect thermal data from the surfaces of roof. It is the most common type of temperature sensor, basically because it is less expensive and easy to use. The time lag and decrement factor is computed from inside-to-outside surface temperature differences across the roof system cross section. The validation of measurement system was performed and results examined and reported. The technique can be used to assess the thermal performance of many different types of roof system.

\section{THERMAL PERFORMANCE ASSESSMENT PROCEDURE (METHODOLOGY)}

'The most widely used parameters for roof thermal evaluation are the thermal resistance, $\mathrm{u}$ and its reciprocal the thermal resistance $\mathrm{R}$. It is considered as the smaller $\mathrm{U}$ (the bigger R), better the thermal performance (Madhumathi, 2012). It depends on the quantities such as time lag and decrement factor which characterizing the periodic changes in heat flow across the roof section. Since, heat flow lags behind temperature differences. These effects are most noticeable in roof systems. One of the parameters to analyze this effect is the thickness of the cross section. This research uses an experimental approach to study these effects. The technique used in this study for assessing the thermal performance of roof system consist an experimental set up, which include three models of RCC slab of varying thickness instrumented with thermocouple and a digital voltmeter. Inner and outer surface temperature data is collected for each model by heating them for a day. Thermal performance based on the periodic heat flow is determined and analyzed by using this measuring technique.

\subsection{Thermocouple Function}

A thermocouple is a device used extensively for measuring temperature. A thermocouple is comprised of at least two metals joined together to form two junctions. One is connected to the body whose temperature is to be measured; this is the hot or measuring junction. The other junction is connected to a body of known temperature; this is the cold or reference junction. Therefore the thermocouple measures unknown temperature of the body with reference to the known temperature of the alternative body. The Peltier effect plays an important role in the working principle of the thermocouple. As per the Peltier effect, while two distinct metals are joined together to form two junctions, emf is generated in the circuit because of the different temperatures of the two junctions of the circuit.
The overall circuit for the operating of thermocouple is shown in the figure 1 below. It comprises of two distinct metals, $\mathrm{A}$ and $\mathrm{B}$, those are joined together to form two junctions, $\mathrm{p}$ and $\mathrm{q}$, which are maintained at the temperatures T1 and T2 respectively. Since the two junctions are maintained at different temperatures the Peltieremf is generated within the circuit and this emf produced is the function of the temperatures of two junctions.

The temperature of the reference junctions is already known, while the temperature of measuring junction is unknown. The output obtained from the thermocouple circuit is calibrated directly against the unknown temperature. Thus the voltage or current output obtained from thermocouple circuit gives the value of unknown temperature directly. The amount of emf developed within the thermocouple circuit is very small as shown in Fig -1, usually it is in mill volts, and therefore digital voltmeter can be used for measuring emf. (Manufacturing-technology)

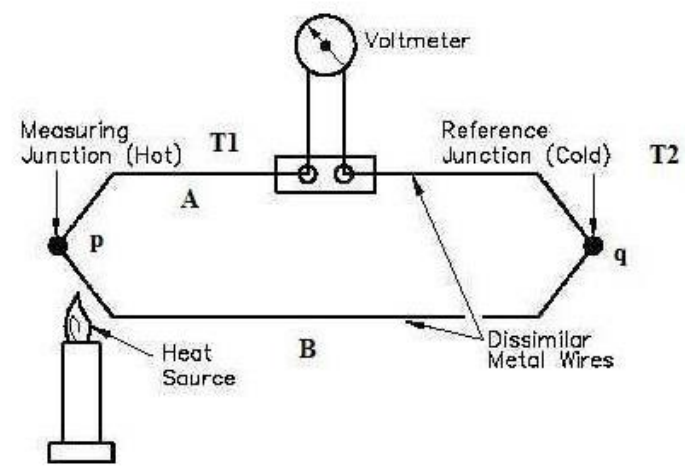

Fig-1: Thermocouple circuit. (Manufacturing-technology)

\subsection{Experimental Procedures}

The experimental set up used includes three models of RCC slab of varying thickness instrumented with thermocouple as shown Fig -2.

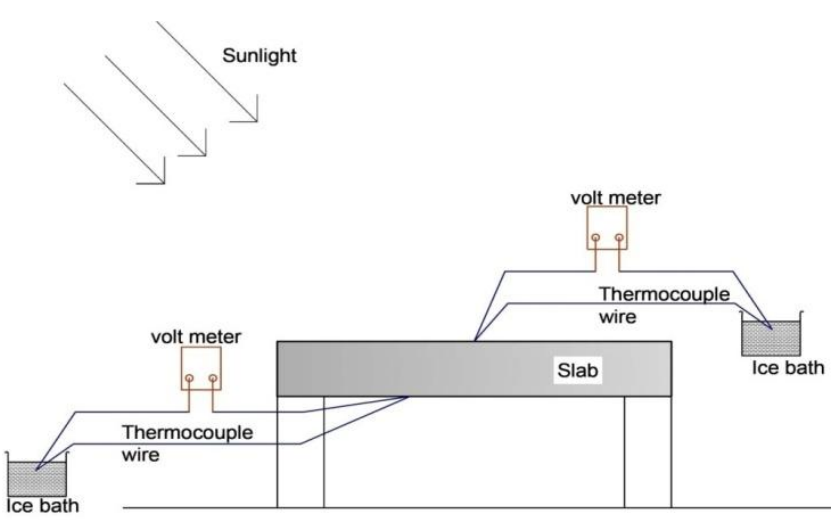

Fig-2: Diagram of experimental set up

By using this experimental set up as shown above inner and outer surface temperature of RCC slab can be measured. This experiment includes mainly 3 steps.

- Calibration of the thermocouple

- Construction of RCC slab models 
- Measurement of surface temperature of RCC slab models using thermocouple.

\subsubsection{Calibration of Thermocouple}

The thermocouple used in this experiment is $\mathrm{T}$ type (Copper-Constantan). The experimental procedure for the calibration of thermocouple is as follows.

Material required: Thermocouple, Thermometer, voltmeter, Ice bath and water (See Fig -3).

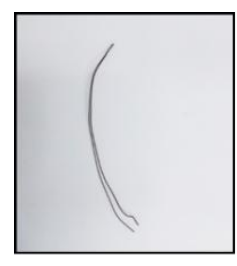

(a)

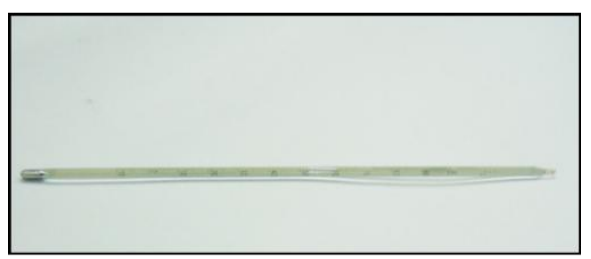

(c)

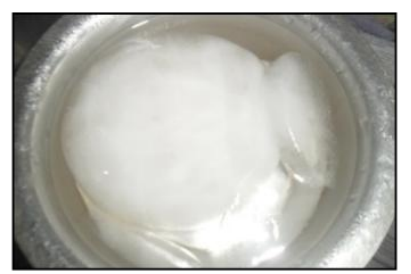

(d)

Fig-3: (a) Thermocouple (b) Voltmeter (c) Thermometer and (d) Water

Steps:

- $\quad$ Take water in a flask to about $75 \%$

- Put thermometer and one junction of thermocouple in water

- Put another junction of thermocouple into the ice bath

- Connect voltmeter to the metal of thermocouple.

- Switch on the heater and take the reading of voltmeter in steps of 5 degree Celsius till 100 Degree Celsius according to the reading in thermometer.

- Tabulate the reading and plot the characteristics. (See Fig -4)

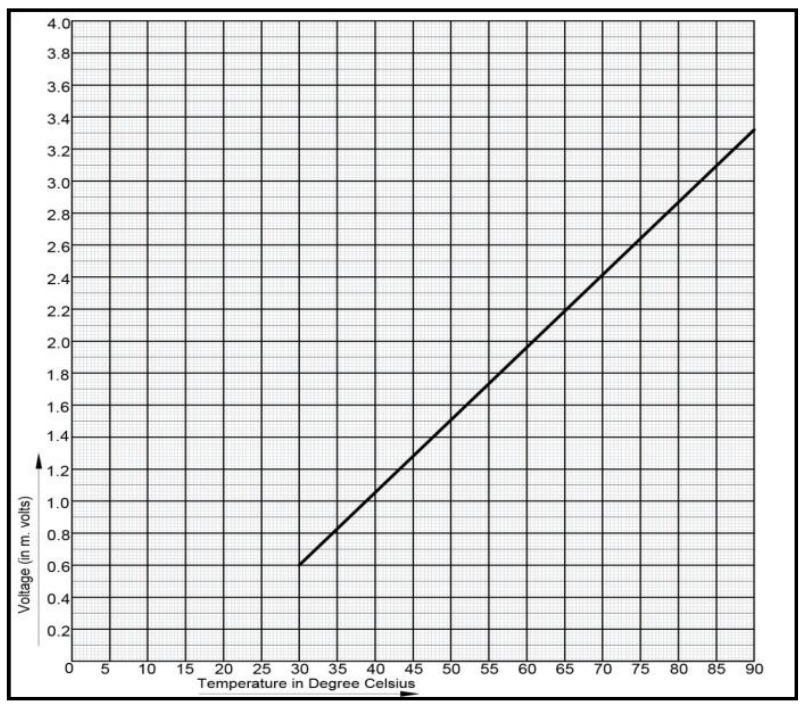

Fig -4: Graph showing the calibration of voltage vs temperature

\subsubsection{Construction of RCC Slab Models}

Three models of RCC slab of dimensions $45 \mathrm{~cm} \times 45 \mathrm{~cm} \times 9$ $\mathrm{cm}, 45 \mathrm{~cm} \mathrm{x} 45 \mathrm{~cm} \times 11 \mathrm{~cm}$ and $45 \mathrm{c} \times 45 \mathrm{~cm} \times 12.5 \mathrm{~cm}$ are constructed. The surface area $(45 \times 45)$ of all models is kept as same and only the thickness of cross section is changed. This is because of the periodic changes in heat flow across the section only depends on the thickness of cross section. The three varying thickness 9,11 and $12.5 \mathrm{~cm}$ selected, since these are the common thickness used in current practices of construction of roof.

Three molds of above dimensions are made out of wooden boards. The grade of concrete mix is M15 as per the IS code 456-2000 and the reinforcement used is $12 \mathrm{~mm}$ dia bars. The concrete is allowed to attain its full strength by keeping it wet for about 14 days. Fig -5 illustrates the construction of slabs.
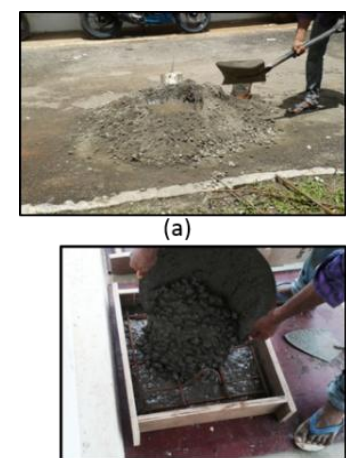

(c)

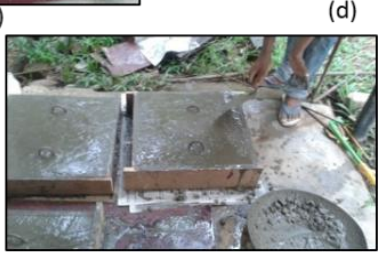

(e)
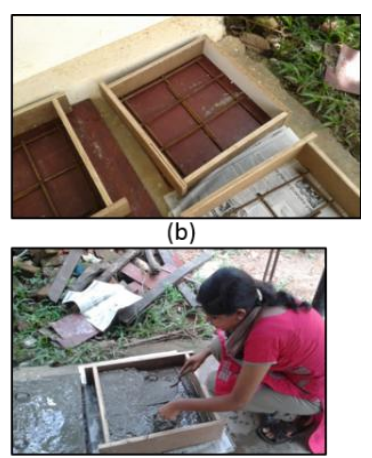

Fig -5: Photos of construction of slabs (a) Mixing of concrete (b) Molds using wooden board (c) Laying of concrete (d) Concreting and (e) Completion of concreting 


\subsubsection{Measurement of Surface Temperature of RCC Slab Models using Thermocouple}

The above mentioned 3 RCC slabs of varying thickness (9, $11 \& 12.5)$ are used for measuring the surface temperature to analyze the periodic heat flow across them. These models are exposed to direct solar radiation in a typical sunny day. Slabs absorbed a great deal of heat which continues to be transmitted across them. The thermocouple instrumental setup (voltmeter and ice bath) is fixed to each surface to take the surface temperature. The readings are taken at time interval of 30 minutes in daylight hours. The readings of voltmeter for external and internal surfaces of each model are recorded.

\section{RESULTS AND DISCUSSION}

The internal and external surface temperature of each slab is measured in terms of voltage from the reading of voltmeter at a time interval of 30 minutes for the whole day. Compared this measured voltage with the calibration curve obtained in the first step of the experiment procedure. And obtain corresponding temperature.

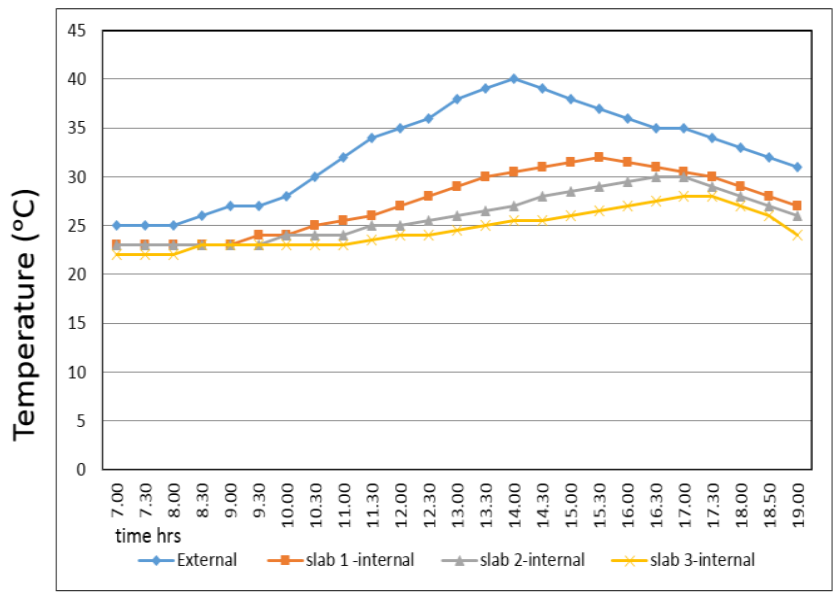

Slab1 $=9 \mathrm{~cm}$ thick, slab $2=11 \mathrm{~cm}$ thick and slab $3=12.5 \mathrm{~cm}$

Fig -6: Graph showing the surface temperature data of each model

The temperature obtained for each surface is plotted as shown in above graph to compare the periodic heat flow. The external surface temperature is almost same for each slab. The internal surface temperature is varying as shown in Fig -6. The internal temperature values are differed in terms of time lag and a decrement factor of the temperature. Time lag refers the time delay between the maximum external and internal temperature of a slab section. The reduction in cyclical temperature on the inside surface compared to the outside surface is known as the decrement. (O H Koenigsberger 1973).

Time lag is increases when thickness of cross section thickness increases from $9 \mathrm{~cm}$ to $12.5 \mathrm{~cm}$. The decrement factor $(\mu)$ is decreases as thickness of cross section increases. Decrement factor is the ratio of maximum outer and inner surface temperature amplitude taken from daily mean. The graphs shown below (See Fig-7, 8 and 9) shows periodic heat flow, time lag and decrement factor of each slab.

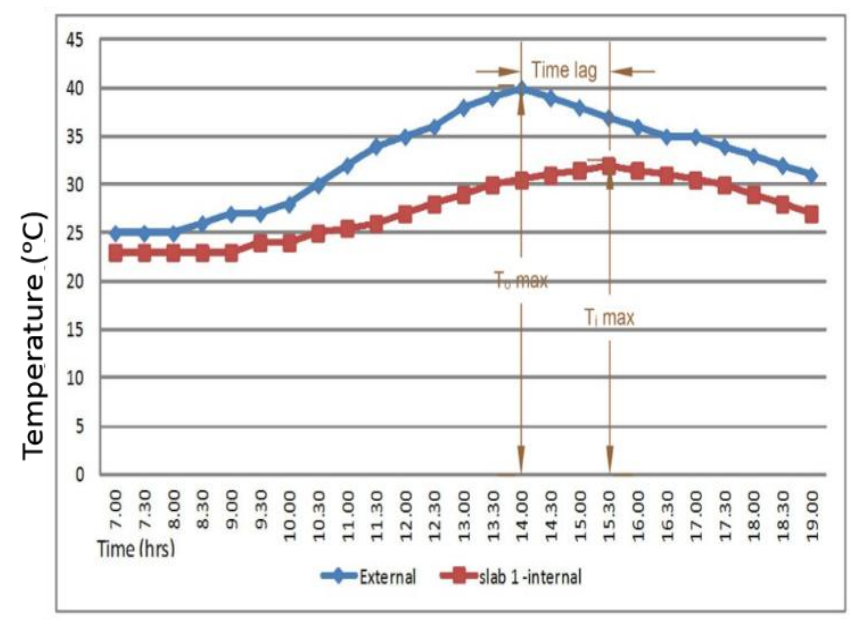

$\mu=\mathrm{Ti} \max /$ To $\max =32 / 40=0.8 \quad$ Time lag $=1 \mathrm{hr} 30 \mathrm{~min}$

Fig -7: Periodic heat flow across slab $1(9 \mathrm{~cm})$

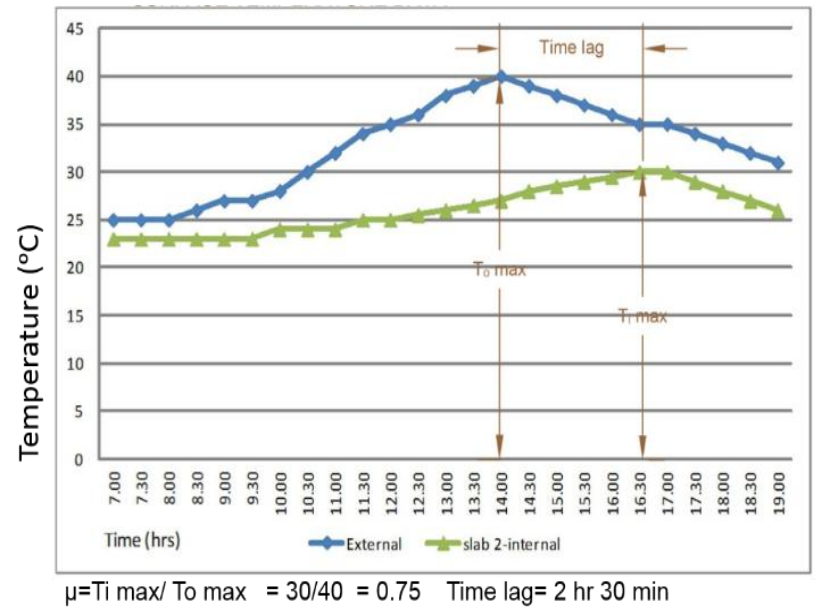

Fig -8: periodic heat flow across slab $2(11 \mathrm{~cm})$

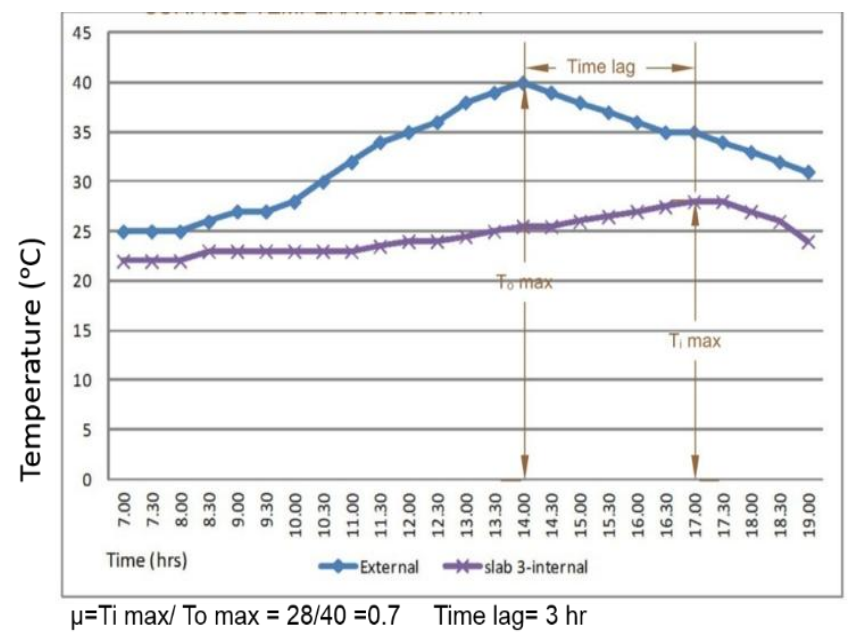

Fig -9: Periodic heat Flow across slab $3(12.5 \mathrm{~cm})$ 


\section{CONCLUSION}

The periodic heat flow across each slab in a typical sunny day is plotted as graph. The parameters that determine the thermal performance of roof is analyzed in terms of time lag and decrement factor. A procedure utilizing the thermocouple in conjunction with voltmeter, can be valuable in determining the thermal performance of roof system Thermally inefficient roof can be identified through the utilization of roof thermal assessment procedures.. Time lag and decrement factor can be determined using this measurement technique and from calibration data of thermocouple. It will help to check the thermal performance against design expectation. It also promotes improved design procedures.

\section{REFERENCES}

[1] A. Madhumathi1, B. M.C. Sundarraja2. "Experimental study of passive cooling of building facade using phase change materials to increase thermal comfort inbuildings in hot humid areas." International journal of energy and environment, 2012: 739-748.

[2] Agrawal, Himanshu. Roof and Wall Insulation-A Key to Energy Conservation and Sustainable Development. Roorke-Uttarakhand: CSIR - Central Building Research Institute- Roorke, 2012.

[3] "Energy." Environmental Building Guidelines for Greater Hyderabad - Ver. 1.2, 2010: 1-6.

[4] Manufacturing-technology. http://www.brighthubengineering.com/manufacturing -technology/53682-what-is-a-thermocouple-howthermocouple-works/.

[5] Matrosov, Yurij A. "Increasing Thermal Performance andEnergy Efficiency of Buildings in Russia: Problemsand Solutions." Proceedings of Thermal performanceof the Exterior Envelopes of Whole Buildings, 2007: 2-7.

[6] H Koenigsberger, T G Ingersell, Alan Mayhew \& S V Szokolay. Manual of Tropical Housing and Building. University press (India) Private Limited, 1973.

[7] "Thermal comfort." www.labeee.ufsc.br. 12 20, 2002. http://www.labeee.ufsc.br/antigo/arquivos/publicacoe s/Thermal_Booklet.pdf.

\section{BIOGRAPHIES}

Dr. K.Thirumaran, involved in the Research field related to the Built Environment and Urban Conservation last few years. Presently he is guiding $7 \mathrm{PhD}$ scholars (research under NIT, Trichy) and has more than 25 years of teaching experience and 7 years of research experience at NIT, trichy.

Jesna Mathew, PG Student, Department of Architecture, National Institute of Technology, Trichy. 